\title{
Every Now and Then, no-futurism faces no sceptical problems
}

\author{
Tim ButTon
}

This paper is published by Blackwell Publishing, on behalf of the Analysis Trust. This is a post-print; that is, it is the full and correct text, including the Correction (also published in Analysis). The definitive version is available at Blackwell. The full citations are:

Button, Tim. 2007. 'Every Now and Then, no-futurism faces no sceptical problems'. Analysis 67.4, pp.325-32. This incorporates the 'Correction to Tim Button, Every Now and Then, no-futurism faces no sceptical problems' in Analysis 68.1, p.95

\begin{abstract}
Tallant (2007) has challenged my recent defence of no-futurism (Button 2006), but he does not discuss the key to that defence: that nofuturism's primitive relation ' $x$ is real-as-of $y$ ' is not symmetric. I therefore answer Tallant's challenge in the same way as I originally defended no-futurism. I also clarify no-futurism by rejecting a common mis-characterisation of the growing-block theorist. By supplying a semantics for no-futurists, I demonstrate that no-futurism faces no sceptical challenges. I conclude by considering the problem of how to interpret the relation ' $x$ is real-as-of $y$ '.
\end{abstract}

Tallant (2007) challenges my recent defence of no-futurism (Button 2006), but does not discuss the key to that defence: that no-futurism's primitive relation ' $x$ is realas-of $y$ ' is not symmetric. I therefore answer Tallant's challenge in the same way as I originally defended no-futurism. Doing so allows me to clarify what no-futurists should believe and to supply a variety of semantic principles for no-futurism. It also shows why no-futurists have nothing to fear from sceptical challenges. This is not to say that no-futurism has no weaknesses, however, and I conclude by suggesting where attacks on no-futurism would be better targeted.

\section{Clarifying no-futurism}

No-futurists hold that the PAST and the PRESENT are real, but that the FUTURE is not. The capitalization indicates that these are not merely temporal indexicals; they capture the ontological privilege that the PRESENT moment has by virtue of being the last moment of time. A no-futurist, of course, believes that she is PRESENT, but this belief may be problematic. Seemingly, if the no-futurist is PRESENT, then all her real PAST predecessors were wrong to think that they were PRESENT. So, by a sceptical induction, the no-futurist should think that her belief is also wrong. In which case, no-futurism collapses (Bourne 2002: 362) ${ }^{1}$

I argued that this problem dissolves by recognising that 'real-as-of' is not a symmetric relation (Button 2006). I can clarify this claim by rejecting a standard

\footnotetext{
${ }^{1}$ Cf. Braddon-Mitchell 2004. 200, Button 2006 131 and Tallant 2007: 84.
} 
characterization of no-futurism, according to which time is represented by a sequence of increasingly large blocks: ${ }^{2}$

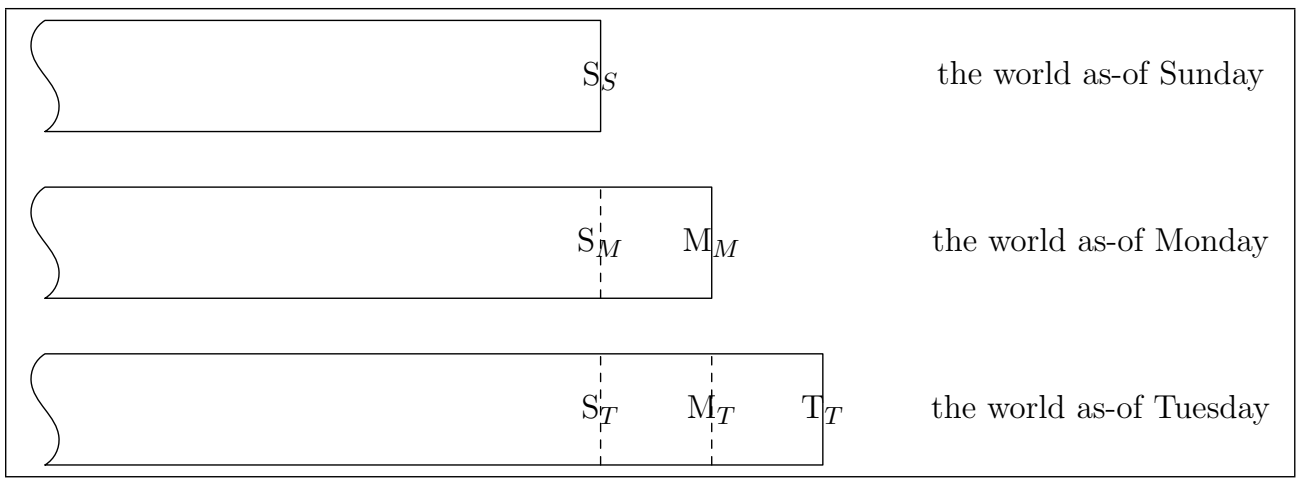

Supposedly, the most recent (bottom) block depicts the world as it is, and the others depict the world as it was ${ }^{3}$ However, several Sundays appear on the diagram: Sunday as-of Sunday (marked as ' $\mathrm{S}_{S}$ '), Sunday as-of Monday (' $\mathrm{S}_{M}$ '), and Sunday as-of Tuesday (' $\mathrm{S}_{T}$ '). This threatens to make time two-dimensional. To avoid this, no-futurists are taken to hold that the whole of reality is depicted by just one block: the most recent. So, if on Tuesday we want to check the truth-value of some sentence-token uttered on Sunday, we must look to $\mathrm{S}_{T}$ (the only Sunday).

Suppose that it is Tuesday. Consider a token utterance, $U$, of 'Sunday is PRESENT' that was uttered on Sunday. For the no-futurist, $U$ is true only if Tuesday is not real. But given the block picture, $U$ was was false, for it neglected $\mathrm{T}_{T}$ 's existence. This is at the heart of the sceptical challenge: all our previous utterances were wrong, so we probably are. (Indeed, if $U$ was false, then the block marked 'the world as-of Sunday' depicts reality as it never was.)

To avoid this problem, we must maintain that $U$ was true: that it was right on Sunday to deny $T_{T}$ 's existence. This requires that the Sunday we consider on Tuesday, when evaluating $U$, corresponds with $\mathrm{S}_{S}$. How could this be possible? Only if the real-as-of relation is not symmetric. The no-futurist should say that, as-of any moment $x$, only $x$ and moments earlier than $x$ are real 4 In that case, Tuesday is not real-as-of Sunday. Nothing about Sunday - not even its relation to Tuesday - is or was altered by Tuesday's being real-as-of Tuesday. Sunday is not 'changed in moving from PRESENT to PAST' (or some such clumsly locution); Sunday as-of Tuesday is identical with Sunday as-of Sunday ${ }^{5}$ Consequently, $U$ was true, as were all similar PAST utterances. The sceptical problem melts away.

Evidently, the block picture is misleading. To model the asymmetry of real-asof, each block would have to be thought of as embedded in the block immediately

\footnotetext{
${ }^{2}$ Cf. Dainton 2001: 69-71

${ }^{3}$ Italicization indicates that the verb is to be read as tensed.

${ }^{4}$ See $\$ 5$ for how to read 'are' here.

${ }^{5}$ Since no properties of (or relations between) moments change with the passage of time, McTaggart's argument also has no purchase against no-futurism. This is, in essence, Lowe's 1998, 47) response to McTaggart.
} 
beneath it in such a way that, as you move from right to left in assessing the truth of past-tensed utterances, you mysteriously move up through the blocks and the blocks beneath disappear. This is a wholly inadequate image, but we should not have expected it to be easy - or even possible - to represent time spatially. To picture time is to aim at a complete description of reality, true for all times. Having denied that real-as-of is symmetric, no-futurists should just deny that such a description is possible, for the total reality of moments 'differs' from moment to moment. The no-futurist must therefore part company with Tooley, who claims 'there can be a complete and consistent description of the world that is not a description from any particular temporal perspective' $\left(1997:\right.$ 16) ${ }^{6}$ This view causes the sceptical problem, but it is this view that my no-futurist explicitly rejects.7

\section{Tallant's challenge}

Tallant (2007: 85) argues that the preceding account does not distinguish 'simple indexical' tense (symbolised as ' $i s$ ') from tense 'that ascribes some component to our ontology' ('IS'). The sceptical problems then returns in the following form:

Each of our predecessors believed that it $I S$ the case that this moment IS PRESENT'. If they believed such, and we believe that 'it IS the case that this moment IS PRESENT', then we must find some reason for thinking that we $A R E$ correct in thinking that our claim $I S$ true, as opposed to thinking that our claim WAS-is-'present' and, hence, WAS-is-true. (Tallant 2007: 86)

Tallant fears that ' $I S$ ' and 'is' can diverge, so that I merely WAS-is right at PAST moments to think 'I AM (PRESENT)'. How should we understand this concern?

Perhaps the worry is that that my account of no-futurism neglects some significant difference between the sentences 'I $A M$ ' and 'I am PRESENT'. This concern is groundless. Bourne's sceptical challenge arose by separating expressions that ascribe ontological privilege from those that are mere indexicals. It does not matter whether this separation is indicated by using different verbs (' $I S$ ' versus ' $i s$ ') or by using different independent grammatical particles ('PRESENT' versus 'this moment'); no additional metaphysical distinction hangs upon this purely grammatical choice. So I can address this concern as I did the original sceptical problem.

I would worry that Sunday $W A S$, but $I S$ not, the last moment of time, only if I believed in an 'objective past' (Tallant 2007; 86) that is invariant from moment to moment: a single moment that is PRESENT from the perspective of anyone at any time. The no-futurist denies the possibility of a moment-invariant description of reality, on the grounds that real-as-of is not symmetric. So, suppose it $I S$ Tuesday. Me-on-Tuesday $S A Y S$ : 'me-on-Monday merely $W A S$ correct to think he $I S$ (PRESENT); I AM (PRESENT)'. Suppose further that, as me-on-Tuesday LOOKS

\footnotetext{
${ }^{6} \mathrm{Cf}$. Tooley 1997: 30, 41, 416.

${ }^{7}$ See Button 2006 133-4 for further details of the no-futurist's response to the sceptical challenge.
} 
at it, me-on-Monday SAID exactly the same thing with regard to me-on-Sunday. As-of Monday, me-on-Tuesday IS not real, since Tuesday is later than Monday. So from me-on-Tuesday's perspective, me-on-Tuesday WAS correct. There is simply no threatening induction. (Cf. Button 2006, 133.)

\section{Semantic considerations}

Perhaps Tallant's worry is that anything with the truth conditions 'Monday $I S$ time's last moment' $I S$ false, so the Monday-token merely $W A S$-(is) true, but $I S$ false. This thought needs some unpacking. A token of the type 'Monday IS PRESENT' IS indeed false on Tuesday if I UTTER it on a Tuesday, but the token in question WAS UTTERED on Monday. To consider this argument, we need to consider how to evaluate the PRESENT truth of PAST utterances, which requires an account of no-futurism's semantics. I shall briefly set aside Tallant's concerns to supply one 8

The semantics of future-tensed statements lies beyond the scope of this paper, so consider a past- or present-tensed token, $U$, made at time $t_{1}$ about some event $E$. First, consider $U$ 's truth-value at $t_{1}$. (The abbreviation '[is/was]' should be treated as follows: if we are at $t$ and we wish to evaluate $U$ 's truth at $t$, read every instance of the abbreviation as ' $i s$ '; if we are at some later moment, read every instance as 'was'.)

(i) $U[$ is/was $]$ true at $t_{1}$ iff either:

(a) $U[$ is/was $]$ present-tensed and $E$ and $t_{1}$ are real-as-of each other; or

(b) $U[$ is/was $]$ past-tensed and, for some $t$ earlier than $t_{1}, E$ and $t$ are realas-of each other.

Next, we require a semantic principle for evaluating $U$ 's truth value at any moment $t_{2}$ which is later than $t_{1}$. Three incompatible principles are available:

(ii) $U[$ is/was $]$ true at $t_{2}$ iff $U$ was true at $t_{1}$.

(iii) $U[$ is/was $]$ true at $t_{2}$ iff either:

(a) $U$ was present-tensed and $E$ and $t_{2}$ are real-as-of each other; or

(b) $U$ was past-tensed and, for some $t_{*}$ earlier than $t_{2}, E$ and $t_{*}$ are real-as-of each other.

(iv) $U[$ is $/$ was $]$ truth-valueless at $t_{2}$.

To see the difference between these principles, suppose that a relieved Gaul exclaimed 'Caesar is crossing the Rubicon!' as Caesar crossed the Rubicon. By (ia), this token was true when Caesar crossed the Rubicon. Hence, if we adopt (ii), this token is

${ }^{8}$ Cf. Tooley's (1997; 200-3) and Bourne's 2002; 368-9) non-token-reflexive semantics, particularly their discussion of truth at a time. This account shares features of Lowe's tokenreflexive account (1998: 45-6), replacing talk of 'simultaneity' with ' $x$ and $y$ are real-as-of each other'. 
true, even though, by (ia), anyone who says in 2007 'Caesar is crossing the Rubicon' says something false. By contrast, if we adopt (iii), the Gaul's token is false, since it is evaluated exactly as if it were a fresh token of the same type. Finally, by (iv), the token is truth-valueless. (One might be motivated to adopt (iv) by the thought that it is as peculiar to ask whether the Gaul's token is true as it is to ask whether Caesar's hair is black.)

Tallant will maintain that the preceding discussion treats all the verbs in (i)(iv) as 'simple indexicals'. He will insist that the no-futurist should consider a set of principles exactly like (i)-(iv), but with all the italicized verbs capitalized to make them ontologically ascriptive. Call the resulting principles (I)-(IV). Suppose that the no-futurist adopts either (III) or (IV). If Tuesday IS PRESENT, then a token on Monday of 'this $I S$ time's last moment' $W A S$ true (by (IA)) and is true (by (ia) and (ii)), but $I S$ not true (by (III) or (IV)). The same considerations apply to all PAST tokens. By a sceptical semantic induction, we reach Tallant's feared conclusion that I merely $W A S$-is right.

The no-futurist could just respond by accepting (II). Then earlier utterances $A R E$ right if and only if they WERE right, and the semantic induction becomes favourable rather than sceptical. Indeed, a favourable induction is available even to no-futurists who reject (II): that every earlier token WAS true suggests that the current token $I S$. Which induction is correct? That we have to ask this question at all indicates that something has gone awry. For the sceptical semantic induction to be a legitimate induction, the tokens in the inductive base and the current token must be relevantly similar. The inductive base comprises PAST tokens, and it is their PASTNESS that RENDERS them not true (everyone, after all, agrees that they WERE true). So the no-futurist will only accept that this base $I S$ relevant to my current token Tuesday IS PRESENT if the no-futurist already believes that the current token IS (or MIGHT BE) a PAST token. That is precisely what the no-futurist denies: by the asymmetry of real-as-of, as-of any moments, there are no later moments.

We are at the heart of the matter. No-futurists would only require a twodimensional semantics (indexical versus ontological) if they held a two-dimensional view of time, but the two-dimensional view was rejected in $\$ 1$. The semantic objection, like the original puzzle, presupposes a metaphysics that no-futurists reject.

\section{$4 \quad$ Immunity to all sceptical challenges}

To prevent further misdirected attacks on no-futurism, it is worth diagnosing the root cause of the sceptical challenges. Tallant begins his challenge with the words 'suppose that we are in the PAST' (2007: 85). No-futurists will immediately interject that this supposition is always false: whenever I $a m$, there are no later moments, so I cannot be PAST. Sceptical problems would indeed arise if no-futurists were committed to something like:

(1) there is exactly one moment $x$ such that, any token of ' $x$ is PRESENT', uttered at any moment $y$, is true. 
Someone who holds this principle will be genuinely troubled by the supposition that she is PAST. Bourne's original problem arises by reading the verbs tenselessly ${ }^{9}$ Tallant's problem arises by reading the verbs as ontologically-ascriptive. Other problems might arise by reading the verbs in some other way. But this is all irrelevant, since no-futurists reject all readings of (1). Since real-as-of is not symmetric, no-futurists instead endorse:

(2) as-of any moment $y$, there is exactly one moment $x$ such that any token of ' $x$ is PRESENT', uttered at $y,[$ is/was $]$ true,

which is compatible with the no-futurist thesis

(3) for any moment $x$, any token of ' $x$ is PRESENT' uttered at $x$ [is/was] true.

Sceptical worries dissolve, for ontological ascription and indexicality are bound together. Tallant omits the asymmetry of real-as-of in his discussion of my solution, but it is all that my solution to the original problem consisted in. It solves his challenge too, and it blocks any sceptical induction from the falsity of PAST statements of no-futurism, because all the relevant PAST statements were true (and, by (ii), still are).

\section{Interpreting 'real-as-of'}

Capitalization of temporal terms was introduced to disambiguate ontology from indexicality. Since we have seen that these do not come apart, the no-futurist can dispense with the convention. Furthermore, all verbs can be read as tensed (unless explicitly stated otherwise), so the demand to italicize verbs can be relaxed. Nofuturists should feel free to write normal English sentences again.

One verb, however, deserves special attention. No-futurists claim that, as-of any moment, only earlier and simultaneous moments are real. Someone might ask: is the 'are' in the thesis to be read as tensed or tenseless? This question misunderstands no-futurism. The 'is' in ' $x$ is real-as-of $y$ ' is neither tensed nor tenseless. The relation ' $x$ is real-as-of $y$ ' is a primitive of no-futurism, and the verb it includes is just a part of that primitive. Tense and PRESENTNESS supervene upon real-as-of relations, and tenseless truths (i.e. truths that are true at every moment) follow in their wake. But it is clearly nonsensical to demand that the relation itself must be either tensed or tenseless.

Attacks on no-futurism should focus on the interpretation of this relation. In particular, some may object that it is impossible for $x$ to exist relative to $y$, without $y$ existing relative to $x$. If this objection carries, then' $x$ is real-as-of $y$ ' cannot be interpreted as ' $x$ exists relative to $y$ '. It will follow that all moments of time exist relative to each other (albeit without being 'real-as-of' each other), and nofuturism will have become a version of the tenseless theory of time, with ' $x$ is realas-of $y$ ' interpreted as some transitive, reflexive, non-symmetric accessibility relation

${ }^{9}$ Cf. Button 2006: 132 
between co-tenselessly-existing objects and moments. This would vindicate Bourne's claim (2002) that the only plausible theories of time are presentism and the tenseless theory.

But why should it be unacceptable to relativize existence? The relation ' $x$ exists relative to $y$ ' is still, for the no-futurist, symmetric within moments, so synchronic metaphysics is unaffected. No-futurists are simply telling us to take seriously the idea that reality as a whole differs from moment to moment. To maintain that this idea is implausible is just to refuse to engage with tensed theories of time altogether 10

\author{
University of Cambridge, Darwin College \\ Cambridge CB3 9EU, UK \\ button@cantab.net
}

\title{
References
}

Bourne, C (2002). 'When am I? A tense time for some tense theorists?'

Australasian Journal of Philosophy, 80, pp. 359-371.

Braddon-Mitchell, D (2004). 'How do we know it is now now?' Analysis, 64, pp. 199-203.

Button, T (2006). 'There's no time like the present'. Analysis, 66, pp. 130-135.

Dainton, B (2001). Time and Space. Chesham: Acumen Press.

Dummetт, Michael (1960). 'A Defence of McTaggart's Proof of the Unreality of Time'. Philosophical Review, 69, pp. 497-504.

Le Poidevin, R, editor (1998). Questions of Time and Tense. Oxford: Clarendon Press.

Lowe, E J (1998). 'Tense and Persistence'. In Le Poidevin (1998), pp. 43-59.

TAllant, J (2007). 'There have been, are (now), and will be lots of times like the present in the hybrid view of time'. Analysis, 67, pp. 83-86.

Tooley, M (1997). Time, Tense and Causation. Oxford: Clarendon Press.

\footnotetext{
${ }^{10}$ Many thanks to Arif Ahmed, who first suggested to me the Dummettian line that tensed theorists should reject the 'prejudice that there must be a complete description of reality' (1960 504), and who was my graduate supervisor when I wrote Button 2006. Thanks to him for comments on this paper, and to Craig Bourne, Hugh Mellor, Michael Potter, an anonymous referee for this journal, and members of the Cambridge Metaphysics Group.
} 